\title{
Prognosis of chronic epilepsy with complex partial seizures
}

\author{
D SCHMIDT
}

From the Department of Neurology, University of Berlin, Berlin, West Germany

SUMMARY Clinical features associated with a successful or unsuccessful response to high dose antiepileptic drug therapy were evaluated prospectively in 82 patients with chronic complex partial seizures. Complete seizure control was observed during high dose drug therapy in 18 patients at plasma concentrations of either $9-35 \mu \mathrm{g} / \mathrm{ml}$ phenytoin, 32 and $40 \mu \mathrm{g} / \mathrm{ml}$ phenobarbitone, $8 \mu \mathrm{g} / \mathrm{ml}$ carbamazepine, or a combination of $25 \mu \mathrm{g} / \mathrm{ml}$ phenobarbitone and $4 \mu \mathrm{g} / \mathrm{ml}$ carbamazepine. Patients who became free of seizures had a markedly lower number of three seizures (range: 1-29) in the year before the high dose treatment as compared to 40 seizures (range: 3-328) in patients with an increased or unchanged seizure frequency $(p<0 \cdot 0001)$. Complex partial seizures without automatism were found only in patients with complete seizure control (22\%). Patients whose seizures remained uncontrolled more frequently gave a history of severe depression or psychotic episodes, clusters of complex partial seizures, two or more seizures per day, and an aura preceding the attack. The results suggest that taking a careful history will uncover clinical features associated with a successful or unsuccessful response to high dose antiepileptic drug therapy in an epileptic out-patient with chronic complex partial seizures.

Complex partial seizures are frequently found among adult patients with intractable epilepsy. ${ }^{12}$ Recent evidence suggests that chronic complex partial seizures can be controlled in $31 \%$ of the patients with high dose single antiepileptic drug therapy. ${ }^{3} \mathrm{~A}$ predictive assessment of the individual seizure prognosis would be valuable for the clinical management. For evaluation of clinical features associated with a successful or unsuccessful response to high dose antiepileptic drug therapy, we studied 82 paients with chronic complex partial seizures referred to a seizure clinic for diagnostic and therapeutic reevaluation.

\section{Patients and methods}

Eighty two patients underwent diagnostic and therapeutic reevaluation for chronic complex partial seizures in the Department of Neurology between October 1974 and December 1980 (table 1). Patients with space occupying

Address for reprint requests: Priv Doz Dr D Schmidt, Department of Neurology, University of Berlin, Spandauer Damm 130, 1000 Berlin 19, West Germany.

Received 30 June 1983 and in revised form 24 May 1984

Accepted 1 June 1984 brain lesions were not included. The patients were seen by the author every 1-3 months in the seizure clinic; the type and the number of seizures were documented by the patient in a calendar. Description of the seizure by the patient and observers was obtained. The type of epileptic seizures was defined according to the classification of the International League against Epilepsy. ${ }^{4}$ Antiepileptic drug monitoring with the enzyme immunoassay EMIT was employed at each consultation. The measurement of antiepileptic drugs was regularly monitored by external quality control. Neurological and psychiatric examination was performed for each patient and clinical drug toxicity was evaluated at each visit. The EEG and the cranial computed tomography findings and social data are not included in this analysis.

The 82 patients entered a prospective trial of high dose therapy with either carbamezapine, phenytoin, phenobarbitone or primidone, if necessary, until clinical toxicity for example nystagmus, ataxia, dizziness, diplopia or unacceptable drowsiness prevented a further dose increment. The lowest plasma concentration of the drug which resulted in complete seizure control was regarded as the individual therapeutic plasma concentration. Complete seizure control including cessation of auras was produced by high dose therapy in 18 patients $(22 \%)$ at plasma concentrations of either $24 \mu \mathrm{g} / \mathrm{ml}$ phenytoin (range: $9-35, \mathrm{n}=$ 14), 32 and $40 \mu \mathrm{g} / \mathrm{ml}$ phenobarbitone derived from primidone therapy, $8 \mu \mathrm{g} / \mathrm{ml}$ carbamazepine, or multiple drug therapy with $25 \mu \mathrm{g} / \mathrm{ml}$ phenobarbitone and $4 \mu \mathrm{g} / \mathrm{ml}$ 
Table 1 Clinical features of 82 patients with complex partial seizures referred for reevaluation of intractable epilepsy to a seizure clinic $\ddagger$

\begin{tabular}{|c|c|}
\hline & Number of patients \\
\hline \multicolumn{2}{|l|}{ Seizure type } \\
\hline Complex partial seizures & 13 \\
\hline $\begin{array}{l}\text { Complex partial seizures and generalised } \\
\text { tonic-clonic seizures }\end{array}$ & 69 \\
\hline Isolated auras & 48 \\
\hline Febrile convulsions & 22 \\
\hline \multicolumn{2}{|l|}{ Status epilepticus } \\
\hline convulsive & 8 \\
\hline complex partial & 11 \\
\hline Infantile spasms & 2 \\
\hline Absence seizures & 13 \\
\hline Simple partial seizures & 3 \\
\hline \multicolumn{2}{|l|}{ Onset of epilepsy } \\
\hline $\begin{array}{l}\text { below age } 10 \\
\text { age } 10-19\end{array}$ & $\begin{array}{l}26 \\
30\end{array}$ \\
\hline over age 20 & 26 \\
\hline \multicolumn{2}{|l|}{ Duration of epilepsy } \\
\hline below 10 years & 10 \\
\hline $10-20$ years & 39 \\
\hline over 20 years & 33 \\
\hline \multicolumn{2}{|l|}{ Etiology } \\
\hline $\begin{array}{l}\text { symptomatic } \\
\text { unknown }\end{array}$ & 51 \\
\hline \multicolumn{2}{|l|}{ Delay of initial drug treatment } \\
\hline less than 1 year & 47 \\
\hline $1-9$ years & 24 \\
\hline more than 10 years & 5 \\
\hline no data & 6 \\
\hline \multicolumn{2}{|l|}{ Family history of } \\
\hline febrile convulsions & 4 \\
\hline epilepsy & 9 \\
\hline paranoid psychotic episodes & 2 \\
\hline \multirow{2}{*}{\multicolumn{2}{|c|}{ Neurological examination }} \\
\hline & \\
\hline $\begin{array}{l}\text { normal } \\
\text { abnormal* }\end{array}$ & $\begin{array}{l}39 \\
43\end{array}$ \\
\hline \multicolumn{2}{|l|}{ Psychiatric examination } \\
\hline normal & 36 \\
\hline abnormal $\dagger$ & 46 \\
\hline
\end{tabular}

*includes both postoperative $(n=8)$ and mild neurological deficits $(n=25)$.

fincludes depression, severe enough to require in-patient care $(n=$ 11), paranoid psychotic episodes $(\mathrm{n}=10)$, neurotic disorders $(\mathrm{n}=$ $20)$, personality disorders $(n=31)$, and suicide attempts $(n=13)$.

$¥$ Age (yr) Mean 37 (range 17-72).

carbamazepine (table 2). The actual numbers of seizures in the 12 months before the trial and the duration of followup in 18 patients with complete seizure control are given (table 2). Fourteen of the 18 patients (No 1-14) were completely controlled by increasing the daily dose of the single antiepileptic drug the patients presented with at the first visit in the seizure clinic without a change of the antiepileptic drug (table 2). Two patients (No 15, 16) could not be controlled by high dose single drug therapy with primidone or phenytoin, but were completely controlled by alternative single drug therapy with phenytoin and carbamazepine, respectively (table 2). In two patients (No 17, 18) who presented with two drug therapy including primidone with either clonazepam or phenytoin, complete seizure control was produced by reduction of two drug therapy to single drug therapy with primidone and phenytoin, respectively (table 2 ).

Sixty four of the 82 patients remained uncontrolled despite high dose therapy with phenytoin, carbamazepine and phenobarbitone alone or in combination (22 patients), two of these drugs alone or in combination (35 patients), or one of these drugs together with either clonazepam, clobazam or valproate (seven patients). The duration of high dose therapy was 37 months $( \pm 24 ;$ SD). The highest plasma concentrations during single or multiple drug treatment for each drug ranged from $34(7-53) \mu \mathrm{g} / \mathrm{ml}$ phenytoin $(\mathrm{n}=58), 10(4-17) \mu \mathrm{g} / \mathrm{ml}$ carbamazepine $(\mathrm{n}=$ $37)$, and $40(12-68) \mu \mathrm{g} / \mathrm{ml}$ phenobarbitone $(n=43)$. The plasma concentrations were higher than $20 \mu \mathrm{g} / \mathrm{ml}$ phenytoin, $6 \mu \mathrm{g} / \mathrm{ml}$ carbamazepine and $20 \mu \mathrm{g} / \mathrm{ml}$ phenobarbitone in $89 \%, 84 \%$ and $81 \%$ of the patients, respectively. Therapeutic drug monitoring was not available during five drug regimens. In 64 of the 82 patients high dose antiepileptic drug treatment resulted in an increased or unchanged seizure frequency in 31 patients, a reduction of seizure frequency of less than $75 \%$ in 21 patients, and a reduction of more than $75 \%$ in 12 patients.

For assessment of clinical characteristics 18 patients who became completely controlled were compared with 64 patients who continued to have seizures and 31 patients with an increased or unchanged seizure frequency.

\section{Results}

Most patients had had chronic epilepsy with complex partial seizures for more than 10 years and reported multiple seizure types. Twenty three per cent gave a history of status epilepticus (table 1). Psychiatric examination was abnormal in $56 \%$, and a suicide attempt was reported by $16 \%$.

The clinical characteristics of patients with and without complete seizure control are compared in table 3 . The most striking difference was a markedly lower number of seizures in the 12 months before high dose treatment in the 18 patients who became free of seizures as compared to the 31 patients with an increased or unchanged frequency of seizures ( $p$ $<0.0001)$. The 18 patients who became seizurefree more often had complex partial seizures without automatisms (22\%), and curiously, a history of status epilepticus with generalised tonic-clonic seizures $(28 \%)$. In contrast, four clinical features were found more frequently in the history of the 64 patients whose seizures were not completely controlled. These are: severe depression or paranoid psychotic episodes (33\%), a cluster of seizures lasting more than two subsequent days $(72 \%)$, two or more complex partial seizures per day $(61 \%)$, and an aura preceding the complex partial seizures in $22 \%$ (table 3). An improvement of the seizure frequency by more than $75 \%$ was noted in one out of 11 patients $(9 \%)$ with one of these four clinical features, in five out of 25 patients $(20 \%)$ with two features, in four out of 19 patients $(21 \%)$ with three features, and in one out of nine patients $(11 \%)$ without any of these features. None of the features appeared therefore to exert any marked influence 
Table 2 Treatment with carbamazepine, phenytoin and primidone, number of seizures in the previous 12 months and duration of follow-up for 18 patients with complete seizure control. The lowest plasma concentration of the drug which resulted in complete seizure control was regarded as the individual therapeutic plasma concentration

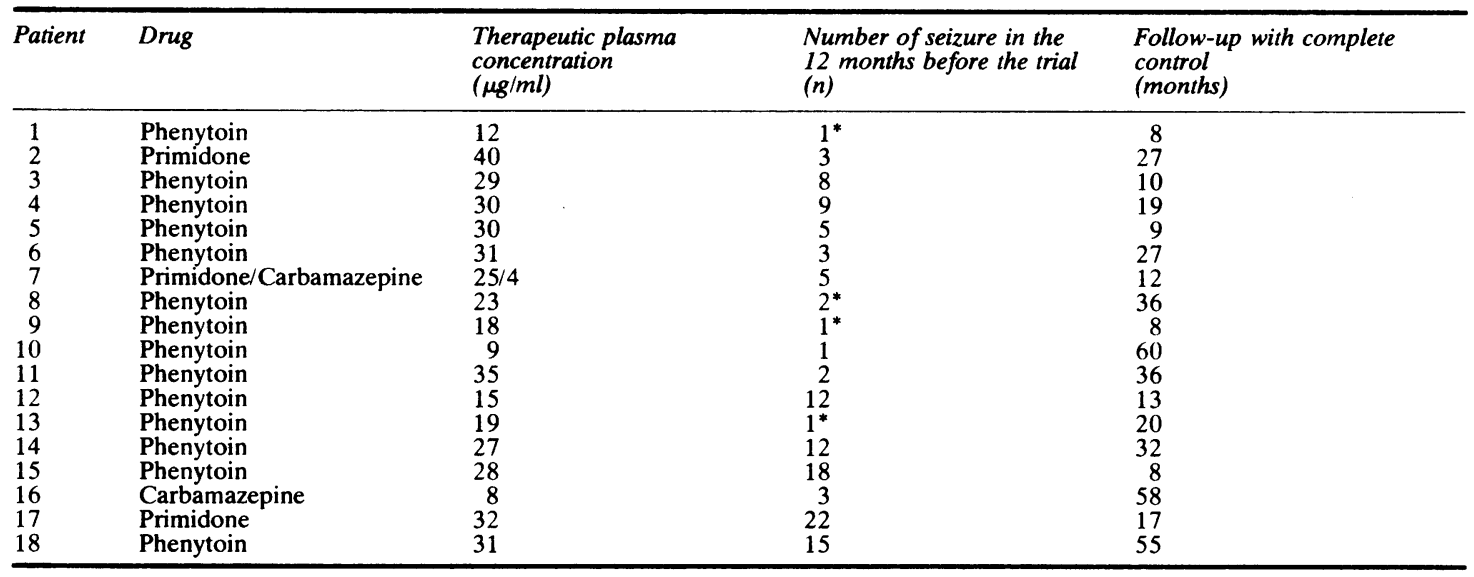

*Single relapse related to reduction of daily dose, previously completely controlled for $2,3,7,12$ years, respectively.

on the relative improvement in patients whose seizures remain uncontrolled.

The 18 patients who became seizure-free gave a history of both complex partial seizures and generalised tonic-clonic seizures. In 11 patients the generalised tonic-clonic seizures were controlled more than 1 year earlier than the complex partial seizures. In four patients both seizure types disappeared simulteneously while generalised tonic-clonic seizures persisted longer than complex partial seizures in two patients. Seven of the 18 patients had isolated auras prior to complete control. In two patients the isolated auras were the last seizure type to become controlled in the course of treatment. The therapeutic plasma concentration for generalised tonic-clonic seizures was $46 \%(16-94 \%)$ lower than for complex partial seizures in five patients, identical in four patients and $71 \%(64-77 \%)$ higher in 2 patients. Patients who were never free of seizures for longer than 6 months $(64 \%$ vs $33 \%, p=0 \cdot 08)$ and female patients were slightly more frequent in the poor prognosis group $(47 \%$ vs $22 \%, \mathrm{p}=0 \cdot 1)$.

Other factors which have not been found to have any appreciable influence on the outcome are multiple seizure types, isolated auras, the onset of the epilepsy with generalised tonic-clonic seizures or complex partial seizures, the age at onset and the duration of epilepsy, the delay of the initial therapy, generalised tonic-clonic seizures occurring at awakening or during sleep, a family history of febrile convulsions or epilepsy, and finally the neurological status of the patient.

Table 3 Clinical features of 18 patients with complete seizure control and of 64 patients who continued to have seizures. In 31 of the 64 patients the seizure frequency was increased or unchanged

\begin{tabular}{|c|c|c|c|}
\hline & $\begin{array}{l}\text { Patients with complete seizure } \\
\text { control }\end{array}$ & $\begin{array}{l}\text { Patients without complete seizure } \\
\text { control }\end{array}$ & $p$ \\
\hline $\begin{array}{l}\text { Median number and range of seizures in } \\
12 \text { months before the trial } \\
\text { Complex partial seizures without automatism }\end{array}$ & $\begin{array}{l}3(1-29) \\
(n=18) \\
422 \% \\
(n=18)\end{array}$ & $\begin{array}{l}40(3-328) \\
(\mathrm{n}=31) \\
0 \\
(\mathrm{n}=64)\end{array}$ & $\begin{array}{l}0 \cdot 0001^{*} \\
(\mathrm{z}=4 \cdot 196) \\
0 \cdot 0034\end{array}$ \\
\hline Complex partial seizures with aura & $\begin{array}{l}(n-10) \\
(n=18)\end{array}$ & $\begin{array}{l}1422 \% \\
(\mathrm{n}=64)\end{array}$ & $0 \cdot 0427$ \\
\hline History of convulsive status epilepticus & $\begin{array}{l}528 \% \\
(n=18)\end{array}$ & $\begin{array}{l}35 \% \\
(n=64)\end{array}$ & 0.0207 \\
\hline Cluster of complex partial seizures & $\begin{array}{l}422 \% \\
(n=18)\end{array}$ & $\begin{array}{l}4672 \% \\
(\mathrm{n}=64)\end{array}$ & 0.0215 \\
\hline Two complex partial seizures per day & $\begin{array}{l}317 \% \\
(\mathrm{n}=18)\end{array}$ & $\begin{array}{l}3961 \% \\
(n=64)\end{array}$ & 0.0225 \\
\hline $\begin{array}{l}\text { Severe depression or paranoid psychotic } \\
\text { episodes }\end{array}$ & $(n=18)$ & $\begin{array}{l}2133 \% \\
(n=64)\end{array}$ & $0 \cdot 0106$ \\
\hline
\end{tabular}

p Fisher's exact $p$ test except * Mann-Whitney-U-test. 


\section{Discussion}

The results suggest that a careful history will uncover clinical features associated with a successful or unsuccessful response to high dose antiepileptic drug therapy in an epileptic out-patient with chronic complex partial seizures. A low seizure frequency before high dose treatment and lack of ictal automatism are associated with a good seizure prognosis while a high seizure frequency before the high dose treatment, clusters of seizures, a history of more than 1 complex partial seizure per day, an onset of the complex partial seizures with an aura and a history of severe depression or paranoid psychosis suggest a guarded prognosis for complete seizure control.

This series of patients who were referred to a seizure clinic for intractable complex partial seizures shares a number of clinical features consistently associated with poor seizure prognosis such as multiple seizure types, childhood onset, abnormal neurological examination, and a high seizure frequency. ${ }^{2}$ Previous prognostic data are available from prospective studies of patients which unfortunately did not include drug monitoring or evidence for high dose antiepileptic drug therapy. ${ }^{56}$

One of the clinical features associated with a good outcome was recognised during the last century by Gowers ${ }^{7}$ who reported that a low seizure frequency before any treatment generally suggested a good prognosis. Recent evidence from another series of 120 patients with complex partial seizures shows a better seizure control in patients with a total of less than six generalised tonic-clonic seizures as compared to patients with one or more generalised tonic-clonic seizures per month before the treatment. ${ }^{8}$ In agreement with this study, the existence of rare generalised tonic-clonic seizures does not compromise the outcome in our series. The unexpected relative excess of status epilepticus in patients with excellent prognosis will need further investigation.

The finding that complex partial seizures without automatism do respond better to drug therapy than those with automatism may be related to the recent proposal that complex partial seizures with an initial motionless stare do benefit more from temporal lobe surgery than patients with automatisms.' If the excellent response to drug therapy or temporal lobe resection has a common pathophysiological basis, a thorough therapeutic reevaluation with a high dose antiepileptic drug therapy may be especially valuable in patients with initial motionless stare before surgery is considered.

The development of clusters and more than one seizure per day-may be -related to the higher frequency of seizures in the group with a poorer out- come and are difficult to evaluate separately in this study. The occurrence of an aura renders the outcome a little less favourable which may be not surprising if an aura is considered a focal seizure element and in adults focal seizures generally carry a poorer treatment prognosis as compared to generalised seizures..$^{10} \mathrm{~A}$ history of severe psychiatric disorder in the uncontrolled patients is compatible with the poorer prognosis of patients with neuropsychiatric handicaps, even in previously untreated epilepsies. ${ }^{211}$

The comparative efficacy of the four antiepileptic drugs cannot be evaluated as the choice of drugs was not randomised. However, all uncontrolled patients received at least one alternative single drug trial or two drug therapy before the epilepsy was considered to be intractable. ${ }^{12}$ Thus, the choice of the antiepileptic drug is not considered to effect the conclusions in this study.

Finally, the data suggest that adequate high dose antiepileptic drug therapy may result in seizure control in $22 \%$ and in significant reduction of seizure frequency in a further $15 \%$ in this group of patients who have been difficult to treat and have been referred to a special clinic. This encouraging result shows that optimum antiepileptic therapy has considerable value even in patients with chronic complex partial seizures. About one third of the patients remain unimproved, however, and are currently being reevaluated for surgical treatment.

I thank I Einicke for the careful determination of antiepileptic drug plasma concentrations and the Deutsche Forschungsgemeinschaft (Schm-448-5-3) for financial support.

\section{References}

' Lund L. Anticonvulsant effect of diphenylhydantoin relative to plasma levels. Arch Neurol 1974;31:289 94.

${ }^{2}$ Rodin E, Klutke G, Chayasirisobohn S. Epileptic patients who are refractory to anticonvulsant medications. Neurology (NY) 1982;32:1382-4.

${ }^{3}$ Schmidt D. Single drug therapy for intractable epilepsy. J Neurol 1983;229:221-6.

4 Commission on Classification and Terminology of the International League against Epilepsy. Proposal for revised clinical electroencephalographic classification of epileptic seizures. Epilepsia 1981;22:489-501.

${ }^{5}$ Currie S, Heathfield KWG, Henson RA, Scott DF. Clinical course and prognosis of temporal lobe epilepsy Brain 1971;94: 173-90.

- Tassinari CA, Roger J. Prognosis and therapy of complex partial seizures with barbiturates, hydantoins, and other drugs. In: Penry JK, Daly DD, eds. Advances in Neurology, Vol 1. New York: Raven Press, 1975:201-19. 
' Gowers WR. Epilepsy and Other Chronic Convulsive Diseases: Their Causes, Symptoms and Treatment. New York: William Wood \& Company, 1885.

${ }^{8}$ Schmidt D, Tsai JJ, Janz D. Generalized tonic-clonic seizures in patients with complex partial seizures: Natural history and prognostic relevance. Epilepsia 1983;24:43-8.

${ }^{9}$ Delgado-Escueta AV, Walsh GO. The selection process for surgery of intractable complex partial seizures: Surface EEG and depth electrography. In: Ward AA, Jr, Penry JK, Purpura D, eds. Epilepsy. New York:
Raven Press, 1983:295-326.

${ }^{10}$ Janz D, Kern A, Mössinger HJ, Puhlmann HU. Rückfallprognose während und nach Reduktion der Medikamente bei Epilepsiebehandlung. In: Remschmidt H, Rentz R, Jungmann J, eds. Epilepsie 1981. Stuttgart: Thieme Verlag, 1983:17-25.

" Shorvon SD, Reynolds EH. Early Prognosis of epilepsy. Br Med J 1982;285:1699-701.

${ }^{12}$ Schmidt D. Two antiepileptic drugs for intractable epilepsy. J Neurol Neurosurg Psychiatry 1982;45:1119-24. 